\author{
О.С. Иссерс \\ Омский государственный университет им. Ф.М. Достоевского \\ (Россия, Омск) \\ isserso@mail.ru
}

\title{
ЛЕКСИКО-ГРАММАТИЧЕСКАЯ АДАПТАЦИЯ В СОВРЕМЕННОМ РУССКОМ ЯЗЫКЕ АНГЛИЦИЗМОВ ИЗ СФЕРЫ МОДЫ (НА ПРИМЕРЕ ЗАИМСТВОВАНИЯ MUST НAVE)*
}

В статье рассматривается лексико-грамматическая адаптация заимствованного из английского языка словосочетания must have, вошедшего в русскоязычный дискурс моды в начале XXI века. Активное использование языковых единиц, реализующих регулятивно-рекомендующую стратегию, является характерной чертой дискурса моды. В современном русском языке одним из лексических репрезентантов данной интенции стало заимствование must have. Процесс адаптации его в русском языке обнаруживается в варьировании языкового кода (латиница либо кириллица), орфографической и морфологической формы, лексической и синтаксической сочетаемости.

Автор отмечает, что заимствование must have /мастхэв ${ }^{1}$ значительно расширило сферу своего функционирования, выйдя за рамки дискурса моды, где оно первоначально фиксировалось. На основании анализа корпусных данных и дискурсивных практик новых медиа установлено, что основные семантические приращения связаны с вхождением данного понятия в сферу потребления любого вида товаров и услуг. Анализ контекстов его употребления показал, что данное словосочетание используется в настоящее время по отношению к очень разным предметам: одежде, косметике, компьютерным программам, фильмам, музыке и даже политическим деятелям. Сочетаемость must-have /мacmхэв в русском языке позволяет конкретизировать значения, ассоциированные с абстрактной сущностью данного понятия.

* Исследование выполнено при финансовой поддержке РФФИ и Правительства Омской области в рамках научного проекта № 18-412-550001.

${ }^{1}$ В дальнейшем, учитывая различные варианты орфографического оформления заимствования в русскоязычных текстах, при цитировании сохраняется то же написание, что в источнике. В остальных случаях используется слитное написание на кириллице и дефисное (в целях разграничения с глагольным словосочетанием) - на латинице, что является отражением тенденции к закреплению данного заимствования в его новой функции. 
В русскоязычных дискурсивных практиках must-have/мacmхэв становится знаком нахождения в тренде, приверженности социально одобряемым моделям потребительского поведения, а также сигналом навязываемых стереотипов, установок, ценностей.

Ключевые слова: мастхэв, must-have, дискурс моды, заимствования, англицизмы, рекламный дискурс.

В отечественной лингвистике дискурс моды привлек внимание исследователей относительно недавно, в то время как в западной традиции теоретическое осмысление семиотики моды и ее вербального кода имеет более чем полувековую историю [Башкатова 2009, Бочарникова 2012, Косицкая 2006, Коньков 2002, Матосян 2004, Хунагова 2013].Поскольку дискурс моды отражает ценности и нормы, характерные для конкретного лингвокультурного сообщества, наблюдения за репрезентацией в языке ценностных ориентиров, формирующих соответствующий стиль жизни, существенно для понимания многих социальных изменений [Башкатова, Чернейко 2008].

Идеологию моды Р. Барт рассматривает как «риторическое означаемое», т.е. как систему социокультурных установок, функций, идей, мотивов, мифов, ценностей и других ментальных образований, включенных в дискурс моды [Барт 2003]. В данной системе, в частности, выделяется такой компонент, как нормативные модели, предписывающие ношение той или иной одежды в соответствии с социокультурным образом, статусом и ситуацией. Нормативные модели в дискурсе моды в значительной степени «опредмечены» стереотипными представлениями о символическом или реальном обладании модными объектами. Современная мода как продукт массовой культуры предлагает модель потребления посредством императива: «это следует носить, чтобы быть модным». В то же время нельзя забывать, что дискурс моды влияет на формирование определенной структуры потребностей и, следовательно, является формой рекламы новых товаров, регулятором поведения потребителей и средством расширения сбыта. Среди стратегий дискурса моды одной из основных можно считать регулятивно-рекомендующую, которая выражается в форме совета, рекомендации, пожелания. Модные советы - одна из популярных рубрик фэшн-журналов.

В связи с этим неотъемлемой чертой дискурсивных практик в сфере моды является активное использование языковых единиц, реализующих регулятивно-рекомендующую стратегию. В современном русском языке одним из лексических репрезентантов данной интенции стало заимствованное из английского словосочетание «must have». Процесс адаптации его в русском языке происходит на наших глазах. Это находит проявление в варьировании языкового кода (латиница либо кириллица), орфографической и морфологической формы, лексической и синтаксической сочетаемости.

Цель исследования - рассмотреть лексико-грамматическую адаптацию заимствования must have в русскоязычном дискурсе моды корпусных данных и дискурсивных практик новых медиа. 
В английском языке модальный глагол must имеет общее значение долженствования и употребляется для выражения необходимости совершения действия в силу определенных обстоятельств, а также для выражения приказания или совета. Слово must в английском языке используется, когда речь идет об устойчивых традициях и законах, будь они моральные или юридические. Вторая часть словосочетания - глагол to have ('иметь, владеть, обладать').

В Кембриджском словаре в значении слова-композита must-have указывается его предметный характер и атрибутивность: «A must-have object is something that many people want to own. The iPod quickly established itself as a must-have device. (https://dictionary.cambridge.org/ru/must-have).

В русскоязычной электронной «Энциклопедии моды» слово дается в дефисном написании; указывается сфера его референции и ситуация номинации - своего рода экспертный договор, фиксирующий статус предмета как «мастхэв».

Macm-хэв (англ. Must-have) - трендовая вещь, которая является главныли хитом и «писком моды». В каждом сезоне маст-хэв объявляется экспертами fashionиндустрии (дизайнерами, редакторами глянцевых журналов, стилистами, байерами, фээн-блогерами и пр.). С английского языка термин дословно переводится как «должен иметь». Понятие «маст-хэв» может относиться к одежде, обуви, аксессуарам, косметике, ароматам и пр. (https:/wiki.wildberries.ru/glossary).

На портале «Что-это-такое.Ру» новое понятие мacm-хэв (must-have) представлено в ироническом осмыслении: «Это что-то, что у вас обязательно должно быть, а иначе вы не хипстер, не админ или не крутая модница. Например, последняя модель айфона - стопроиентный маст-хэв любого хипстера, а мощный игровой ноутбук - абсолютный маст-хэв любого гика. В этом сленговом словечке - сила гнева, пламя страсти, и пристрастье к потребленью чуют люди в этом слове» (https://chto-eto-takoe.ru/must-have).

Электронный «Словарь молодежного сленга» трактует must have (в раздельном написании) как «предмет первостепенной надобности и постоянного пользования» (http://teenslang.su/id/15763). По приведенным в словаре примерам можно судить о грамматической адаптации и варьировании орфографической формы неологизма.

Нашел очередное маст-хэв приложение. Маска с водорослями - мой мастхэв. Вот мой списочек мастхэв плагинов. А для меня мастхэв - это корректирующее белье. Маст-хэв для фанатов Монти Пайтона. Маст-хэв сезона - красный тренч. Ну, я, конечно, выпендрилась немного с ржаной мукой, не настолько она у меня маст-хэв. Что должно быть в машине из музыки из серии мастхев? Предлагаю тут поделиться списком программ которые, так сказать, «мастхев», в смысле должны быть у всех [там же].

Национальный корпус русского языка отражает семантическую и морфологическую специфику использования словосочетания must have в русскоязычных текстах весьма ограниченно. Для поиска использовались основной корпус и газетный подкорпус НКРЯ.

По запросу на вариант написания латиницей (must have, must-have) в газетном корпусе найдено 17 вхождений, из них 9 - англоязычные тексты с глагольной 
конструкцией, выражающей модальность: 'должно быть была' (в т. ч. название песни из к/ф «Красотка» — «It must have been love»). В основном корпусе в 8 документах обнаружено 8 вхождений, после снятия омонимии - 6, в т. ч. 3 встречаются в произведениях П. Головина, посвященных компьютерным играм (2004), 1 у Пелевина (2011), остальные два - в публицистических текстах (2012 и 2015 гг.).

На запрос в русской транслитерации и в раздельном написании «маст хэв / маст хев» в основном корпусе было найдено два примера, оба - на форумах. В одном обсуждалась кинотрилогия «Блейд» (2008-2010 гг.):

Первая часть - мастхэв, вторая часть -маст си.

Во втором случае словосочетание употреблено в дискуссии о книге: $B$ любом случае маст хев, даже если не очень захватывающее чтение (2012).

В слитном написании обнаружено 2 примера в газетном корпусе и ни одного в основном. В газетном на запрос мастхэв / мастхэв, обнаружено одно вхождение с Э и одно - с E:

... Ещуе один мастхэв - диадема. Во Франции каждая уважающиая себя принцесса имела корону» (КП, 20.08.2013).

...У каждой интеллигентной дамы обязательно дома должны были стоять книжечки Хмелевской, это было, как сейчас говорят, "мастхев". (КП, 07.10.2013)

В НКРЯ также не обнаружены производные от мастхэв прилагательные и глаголы.

Значительно шире данное словосочетание представлено в новых медиа - электронных версиях СМИ, социальных сетях, обсуждениях на форумах и пр. Анализ контекстов его употребления показал, что данное словосочетание используется в настоящее время по отношению к очень разным предметам: одежде, косметике, компьютерным программам, фильмам, музыке и даже политическим деятелям. Сочетаемость must-have/ мaстхэв позволяет конкретизировать значения, ассоциированные с абстрактной сущностью данного понятия.

Статистика сервиса «Яндекс. Директ», предназначенного для поиска наиболее удачных словосочетаний для контекстной рекламы, показывает, что в марте 2016 г. на Яндексе было сделано 17074 запросов со словосочетанием musthave (в слитном написании). Из этих запросов нами были отобраны те, которые имеют отношение к дискурсу моды или связаны с обозначением чего-то необходимого: musthave 2016 - 480; musthave лето 2016 - 190; musthave осень - 87; musthave одежда 261; musthave платья - 85; musthave список вещей - 77; musthave Крыгиной — 241 (прим. Елена Крыгина - стилист, постоянно употребляющий данное словосочетание в своих публикациях); musthave программы - 84; musthave android - 125 и т. д.

Приведенные цифры свидетельствуют о высокой частотности исследуемого заимствования. Анализ контекстов его употребления показал, что оно используется в настоящее время по отношению к очень разным предметам, отнюдь не ограниченным миром моды: к одежде, косметике, компьютерным программам, произведениям искусства и др.

Чем руководствоваться при планировании долгожданного шопинга и как выглядит список основных маст-хэвов лета 2014? 
WomanJournal.ru предлагает свой вариант тиst have для твоей косметички. На этом мы завершаем обзор яблочных тиst-have программ.

Маст-хэв для фанатов Монти Пайтона.

Милье сообщницы, подскажите, сушка для овощей - это маст-хэв?

Продолжаем рубрику тиsthave о том, что просто необходимо иметь в кажәдм доме. Сегодня это книги.

Обязательный тust have для новорожденного.

Не дай Бог, чтобы эти приспособления стали для всех мастхевом (о приспособлении для разрезания таблеток).

Словосочетание must have стало настолько популярным, что его активно применяют в качестве названия нейма (названия): журнал Must. Have. Style; салон Must have tattoo; MustHave - это и маркетинговое агентство, и бюро элитной недвижимости, и кафе-ресторан, и т.д.

Чаще всего заимствованная единица устанавливает семантико-синтаксические связи со следующими существительными: список (список мастхэвов), продукт (маст-хэвы - это продукты, проверенные не только временем, но и мнением топвизажистов всего мира), коллекция (очень позитивная базовая коллекция - маст хэв), серия (лучший сборник плагинов из серии Must Have), вещь (вот девять musthave вещей, которые должны быть в гардеробе любой женщины), тема (публикации на тему: must-have), категория (мои косметические средства категории «тиst have».), стратегия (Если руководствоваться стратегией тust have, то вы значительно сэкономите и оградите себя от импульсивньх покупок), товары (конечно, список 5 тиst-have товаров у каждого индивидуальный).

Атрибутивные словосочетания актуализируют, прежде всего, семантику престижа и моды: must-have может быть обязательным (Обязательный must-have этой весны - пышная юбка-миди), основным (основной тиst-have этой весны), актуальным (список актуальных маст-хэвов лета), однозначным (Сарафан - однозначный тиst-have в летнем гардеробе каждой моднииь), неувядающим (Неувядаюший must-have сезона - асимметричная юбка), сексуальным (Юбка-карандаи - сексуальный тиst-have осени).

Косвенным свидетельством расширения значения могут служить словосочетания с прилагательными, конкретизирующими сферу актуализации must-have: коcметический, уходовый, кухонный, компьютерный и т. д.

В словосочетаниях с must-have регулярно актуализируются посессивные отношения, где на передний план выходит личность обладающего вещью субъекта: ведь именно через его шкалу ценностей определяется необходимость и востребованность предмета. Поэтому частотны сочетания с родительным принадлежности (мастхэв Елень Крагиной) и притяжательными местоимениями — в первую очередь с «мой» (я хочу рассказать вам про мой тиst have набор).

В современных дискурсивных практиках представлены многочисленные словосочетания с must-have, включающие маркеры хронотопа, что объясняется семантикой моды и актуальности: must-have осени, must-have сезона, must-have июля, musthave недели, must-have 2017 и пр.). 
Сочетания с глаголами подчеркивают предметный характер денотата, обозначаемого как must-have, и имплицитно указывают на основных участников ситуации: того, кто рекомендует, и адресата совета, который принимает решения (выбирает, покупает, инвестирует в...).

Must-have можно

- представлять (представляю вашему вниманию 10 must have этой осени).

- переписывать (маст хэв полностью переписан)

- собирать (так называемые «мастхэв» приложения, нужные всем).

- купить (какие маст-хэвы можно купить только в аптеках Франции?)

- выбирать (интересно, что кто-то выграл мои маст-хэвы).

- копировать (модные блогеры не спешат копировать этот «тиst have»).

- носить (5 маст-хэвов, которые носят редакторы глянца этой весной)

- обсуждать (давайте обсудим маст-хэвы предстоящей весны)

- определять (мастхэв определяем не мы, а мода).

\section{Must-have может}

- выглядеть (посмотрим, как выглядит этот must have).

- приходить на помощь (приходит на помощзь must-have -- классический тренч).

- приобретать массовый характер (Во всём мире тиst have уже приобрел массовый характер и является настоящей философией в области моды).

- а также с ним можно знакомиться (начинаем знакомиться с актуальныли must have летнего сезона 2016).

- в него можно инвестировать (инвестируем в осенние тиst haves).

Таким образом, в результате анализа текстов электронных СМИ и блогосферы можно выделить проективные смыслы, представляющие собой содержание понятия: must-have - это вещь (ее можно носить, купить, выбрать); творческий продукт (его можно представлять, копировать, коллекционировать); человек (он может быть сексуальным, приходить на помощь, с ним можно познакомиться); текст (его можно переписать), продукт массового сознания, ценность (может приобретать массовый характер); утверждение, мнение (его можно обсуждать); проект (в него можно инвестировать).

Наиболее семантически близкими понятиями к исследуемому являются сnuсок, коллекция, вещьь, товар, продукт, категория, тема, стратегия. Анализ перечня семантически близких понятий позволяет сделать вывод о принадлежности данного выражения к рекламному дискурсу в большей степени, чем к дискурсу моды. T.e. must-have - это не столько модные рекомендации и советы, сколько разработка маркетологов и редакторов глянцевых журналов для увеличения спроса на вещи. Это подтверждают собственно коммерческие объявления, где в результате компрессии must-have / мaстхэв выполняет функцию единственного аргумента:«ЭПЛ - якутские бриллиантыл» - интернет-магазин роскошных изделий с бриллиантами. Миsthave. Наш телефон: 8-800-333-67-37. 
Об этом же свидетельствует употребление слова в функции хэштега: \#Мастхэв. АТЕЛЬЕ. Бумага для скрапбукинга оптом.

Интересно, что для адресата подобной аргументации истинное намерение отправителя не остается неразгаданным. Так, на одном из компьютерных форумов пользователи обсуждают новинку: «...Я бы не сказал, что это такой уж "мастхэв"...

iDialer - альтернативная номеронабиралкаб нафикмастхэвить? (https:// forum. onliner.by/viewtopic.php?t=768318\&start=980).

Грамматическая адаптация заимствования проявляется в склонении по образцу мужского рода, образовании форм множественного числа (в т. ч. и в написании на латинице - musthaves) и появлении дериватов мастхевный / мастхэвный, мастхэвить и др.

Так, поиск по запросу мастхэв дает список, где представлены и аналитические словосочетания с мастхэв (мастхэв, маст-хэв), так и грамматически адаптированные, причем последние явно преобладают:

8 мастхэв вещей осенне-зимнего гардероба 2017-2018. 11 мастхэвов на каждый день. Мои мастхэвы косметики.

В новых медиа широко представлены производное прилагательное и глагол:

Вещь дня - мастхэвный ироничный свитшот от российского спортивного бренда... В этой модели есть все, чтобы сделать ее мастхэвом сезона.

(https://www.cosmo.ru/fashion/news/18-01-2018)

Коктейль мастхэвный: творог, молоко, несколько клубничек для запаха (http:// xn--80akjgbibji6bu4f.xn--p1ai/2016/04/21)

Вот мы часто говорим - мой косметический мастхэв, мой уходовый мастхэв, мой кухонный мастхэв - мастхэвить сейчас стало своего рода мейнстримом. (отзыв по поводу ароматизатора воздуха ZARA) (http://irecommend.ru/taxonomy/ term/415048)

Употребление производного мастхэвный с оценочным значением стимулирует образование превосходной степени сравнения по модели качественного прилагательного: Самый мастхэвный мастхэв!!! (из отзыва на сайте (http://irecommend.ru/ content/samyi-mastkhevnyi-mastkhev).

\section{Выводы}

Английское заимствование must have/must-have, вошедшее в русский язык, по нашим предположениям, в нулевые годы XXI века, значительно расширило сферу своего функционирования, выйдя за рамки дискурса моды, где оно первоначально фиксировалось. Основные семантические приращения связаны с вхождением данного понятия в сферу потребления любого вида товаров и услуг и, соответственно, коммерческого (консьюмеристского) дискурса. При этом, с одной стороны, в русскоязычных дискурсивных практиках мастхэв становится знаком нахождения в тренде, приверженности социально одобряемым моделям потребительского поведения, а с другой - сигналом навязываемых стереотипов, установок, ценностей. Последнее обнаруживается в критическом отношении к предметам 
потребления (в том числе и духовного), маркированным мастхэв, и служит источником иронического переосмысления.

Активное использование данного маркера в сфере рекламы, продаж и в фейковых отзывах потребителей ускорило семантическую и морфологическую адаптацию заимствования, а также стимулировали деривационную активность производящего слова.

Отдельного исследования требует орфографическая форма заимствования, которое фиксируется в 6 вариантах на кириллице и в 2-х на латинице.

\title{
Литература
}

Барт Р. Система моды. Статьи по семиотике культуры / Пер. с фр., сост. С. Н. Зенкина. М.: Издательство им. Сабашниковых, 2003. 512 с.

Башкатова Д. А. Современный русский дискурс моды: автореф. дис. канд. филол. наук. М., 2009. 25 с.

Башкатова Д.А., Чернейко Л.О. Философско-лингвистический аспект изучения моды // Филологические науки. 2008. №2. С.86-98.

Бочарникова М.M. Англоязычные заимствования в дискурсе российских телевизионных программ о моде (на материале наименований одежды) // Ярославский педагогический вестник. 2012. № 2. Т.1. С.188-191.

Косиикая Ф.Л. Каталог моды как симфония дискурсов // Вестник ТГПУ. 2006. — № 9(60). С. 35-40.

Коньков В. И. Журнал мод как стилевая система // Вестн. С.-Петерб. ун-та. Сер. 2. История, языкознание, литературоведение. - СПб., 2002. Вып. 4. С. 120-121.

Матосян А.C. Заимствования в терминологии моды XX-XXI вв. // Русский язык : ист. судьбы и современность; II Междунар. конгресс исследователей рус. яз., 18-21 марта 2004 г., Москва, МГУ им. М.В.Ломоносова. М., 2004. С. 191-192.

Хунагова А. Р. Мода в рекламном дискурсе (на материале русского и английского языков) // Вестник Адыгейского государственного университета. Серия 2. Филология и искусствоведение. 2013. №3 (126). С.113-117.

\author{
O.S. Issers \\ F. M. Dostoevsky Omsk State University. \\ (Russia, Omsk) \\ isserso@mail.ru
}

\section{LEXICO-GRAMMATICAL ADAPTATION OF ENGLISH LOANWORDS OF FASHION IN MODERN RUSSIAN (AS ILLUSTRATED BY THE LOANPHRASE MUST HAVE)}

The article deals with the lexical-grammatical adaptation of the phrase "must have", borrowed from English and included into Russian discourse of fashion at the early XXIst century. The active use of linguistic units that implement a regulatory and permissive 
strategy is a characteristic feature of the discourse of fashion. In modern Russian, this strategy is manifested on the lexical level, and one of the examples of it is the loan expression "must have ". The adaptation of the expression in the Russian language is manifested in various ways including the variation of the linguistic code (Latin or Cyrillic), orthographic and morphological form, lexical and syntactic compatibility.

The author demonstrates that the phrase 'must have' has significantly expanded the scope of its functioning, going beyond the discourse of fashion, where it was initially used. Based on the analysis of corpus data and discursive practices of new media, it is established that the semantic expansion of the phrase resulted mainly from its use in the sphere of consumption of any kind of goods and services. The analysis of the contexts where the phrase is used showed that it currently refers to very different objects: clothes, cosmetics, computer programs, films, music and even politicians. The compatibility of the phrase must-have makes it possible to specify abstract ideas that are associated with the concept.

In the Russian-speaking discourse practices, the use of must have has becomes the sign of following a trend, of adherence to socially approved patterns of consumer behavior, as well as a signal of imposed stereotypes, attitudes, and values.

Keywords: must-have, fashion discourse, loan words, English loan words, advertising discourse.

\section{References}

Barthe R. [Fashion system. Articles on semiotics of culture]/ Per. s fr., sost. S. N. Zenkina. Moscow.:Izdatel'stvo im. Sabashnikovyh Publ., 2003. 512 p. (In Russ.)

Bashkatova D. A. [Contemporary Russian discourse of fashion]. Avtoref. dis. kand. filol. nauk. Moscow, 2009. 25 p. (In Russ.)

Bashkatova D. A., Chernejko L. O. [Philosophical-linguistic aspect of the study of fashion] // Filologicheskie nauki. 2008. №2, pp.86-98. (In Russ.)

Bocharnikova M. M. [English loanwords in the discourse of Russian TV programs about fashion (based on names of clothes)] // Yaroslavskij pedagogicheskij vestnik. 2012. №2. T.1. Pp.188-191. (In Russ.)

Kosickaya F. L. [Catalog of Fashion as a Symphony of Discourses] // Vestnik TGPU. 2006. № 9(60), pp.35-40. (In Russ.)

Kon'kov V.I. [The fashion magazine as a style system]// Vestnik S.-Peterb. un-ta. Ser. 2. Istoriya, yazykoznanie, literaturovedenie. - SPb., 2002. Vyp. 4, pp. 120-121. (In Russ.)

Matosyan A. S. [Loan words in the terminology of fashion XX-XXI centuries] // Russkijyazyk :ist. sud'byisovremennost'; II Mezhdunar. kongressissledovatelejrus.yaz., 1821 marta 2004 g., Moscow, MGU im. M. V. Lomonosova. M., 2004. Pp. 191-192. (In Russ.)

Hunagova A.R. [Fashion in the advertising discourse (based on Russian and English languages)] // Vestnik Adygejskogo gosudarstvennogo universiteta. Seriya 2. Filologiya i iskusstvovedenie. 2013. №3 (126). Pp.113-117. (In Russ.) 